\title{
Estimating the components of the sensible heat budget of a tall forest canopy in complex terrain
}

\author{
U. Moderow • C. Feigenwinter • C. Bernhofer
}

Received: 3 November 2005 / Accepted: 16 October 2006 / Published online: 29 November 2006

(C) Springer Science+Business Media B.V. 2006

\begin{abstract}
Ultrasonic wind measurements, sonic temperature and air temperature data at two heights in the advection experiment MORE II were used to establish a complete budget of sensible heat including vertical advection, horizontal advection and horizontal turbulent flux divergence. MORE II took place at the long-term Carbo-Europe IP site in Tharandt, Germany. During the growing period of 2003 three additional towers were established to measure all relevant parameters for an estimation of advective fluxes, primarily of $\mathrm{CO}_{2}$. Additionally, in relation to other advection experiments, a calculation of the horizontal turbulent flux divergence is proposed and the relation of this flux to atmospheric stability and friction velocity is discussed. In order to obtain a complete budget, different scaling heights for horizontal advection and horizontal turbulent flux divergence are tested. It is shown that neglecting advective fluxes may lead to incorrect results. If advective fluxes are taken into account, the sensible heat budget based upon vertical turbulent flux and storage change only, is reduced by approximately $30 \%$. Additional consideration of horizontal turbulent flux divergence would in turn add $5-10 \%$ to this sum (i.e., the sum of vertical turbulent flux plus storage change plus horizontal and vertical advection). In comparison with available energy horizontal advection is important at night whilst horizontal turbulent flux divergence is rather insignificant. Obviously, advective fluxes typically improve poor nighttime energy budget closure and might change ecosystem respiration fluxes considerably.
\end{abstract}

U. Moderow $(\varangle) \cdot$ C. Bernhofer

Institute of Hydrology and Meteorology, Department of Meteorology, Technische Universität Dresden, Dresden 01062, Germany

e-mail: uta.moderow@forst.tu-dresden.de

C. Feigenwinter

Institute of Meteorology, Climatology and Remote Sensing, University of Basel, Basel,

Switzerland

C. Feigenwinter

Unitè de Physique des Biosytèmes, Gembloux, Belgium 
Keywords Advection - Divergence $\cdot$ Energy budget $\cdot$ Sensible heat flux

\section{Introduction}

In many studies that use micrometeorological methods, the net ecosystem exchange (NEE) between atmosphere and the surface of interest is determined as the sum of the vertical turbulent flux and the storage beneath the eddy flux sensors (Aubinet et al. 2000; Baldocchi et al. 2000; Wilson et al. 2002). The vertical and the horizontal advective fluxes are typically neglected. However, heterogeneous surfaces require that these fluxes are taken into account.

The eddy-covariance method (EC method) has an outstanding importance for the estimation of turbulent fluxes and is widely used in describing and studying the ecosystem response to climate (Goulden et al. 1996; Valentini et al. 1996; Aubinet et al. 2001, 2005; Pilegaard et al. 2001; Valentini 2003). Nevertheless this method does have some shortcomings, and especially at night with stable atmospheric stratification, fluxes are underestimated by the EC method, because non-turbulent processes (i.e. storage and advection) become more important, but are not considered properly (Aubinet et al. 2000, 2003, 2005). Therefore, recently more emphasis has been placed on advective processes, primarily to improve estimates of the net ecosystem exchange of $\mathrm{CO}_{2}$ at complex sites (Lee 1998; Baldocchi et al. 2000; Paw U et al. 2000; Lee and $\mathrm{Hu}$ 2002; Aubinet et al. 2003, 2005; Feigenwinter et al. 2004; Staebler and Fitzjarrald 2004; Marcolla et al. 2005).

The impact of advection on the energy balance has been considered in several studies (e.g. Blanford et al. 1991; Bernhofer 1992; Lee 1998; Panin et al. 1998; Bernhofer and Vogt 1999; Paw U et al. 2000; Lee and Hu 2002; Wilson et al. 2002) and is still poorly understood. Blanford et al. (1991) presented circumstantial evidence that over an irrigated pecan orchard much of the latent energy may have been transported by non-turbulent processes resulting in poor energy closure. On a daily basis Bernhofer and Vogt (1999) found no improvement in closure when including vertical advection, and vertical advection was suspected by Lee and $\mathrm{Hu}$ (2002) to contribute to the lack of energy closure. Lee (1998) found improvement of energy closure at night when including vertical advection, but not at day, while Paw U et al. (2000) speculated that advection may be important for sensible heat at night and day, but only during the day for latent heat flux, since only small values occur at night. A similar statement is made by Wilson et al. (2002).

Less is known about the horizontal turbulent flux divergence (in the following referred to as divergence or horizontal flux divergence), which has been experimentally neglected until now. Yi et al. (2000) pointed out that, under convective conditions, the horizontal flux divergence is much smaller than the vertical turbulent flux; this agrees with Wyngaard et al. (1971) and Lee (1998). Finnigan (1999) stated that the assumption that the horizontal flux divergence is always much smaller than the vertical turbulent flux cannot be anticipated. Lee (2004) examined the horizontal flux divergence on the basis of the simple mixing-length analogy; he emphasized that this term cannot be evaluated in isolation from other terms in the mass conservation equation, and that the horizontal flux divergence is generated by gradient diffusion and by correlation between the vertical and horizontal velocities. Staebler and Fitzjarrald (2004) argued that the horizontal flux divergence may be significantly important $(10 \%$ of vertical turbulent flux and $30 \%$ of the mean horizontal advection respectively), 
underlining the need of further analysis at the same time. Also, an estimation of this flux divergence is made for sensible heat based on an extended measurement campaign in 2003.

The aim of the present work is to establish a complete budget of sensible heat including vertical advection, horizontal advection and the horizontal flux divergence. Furthermore, an attempt is made to evaluate the importance of each budget term in relation to available energy.

We used observations from the advection experiment MORE II (More measurements in the Ore mountains), which took place at the anchor station Tharandter Wald (Germany) in the summer and autumn 2003. This experiment was part of VERTIKO, a project funded by the German Ministry of Education and Research within the programme AFO 2000 (Bernhofer and Köstner 2003). MORE II aimed at measuring all relevant parameters for an accurate estimation of non-turbulent advective fluxes of $\mathrm{CO}_{2}$ in a soil-vegetation-atmosphere volume.

\section{Site and instrumentation}

\subsection{Site}

The anchor station Tharandter Wald (ASTW) is one of the long-term monitoring stations within the European carbon and water flux programmes from EUROFLUX to Carbo-Europe IP and serves also as a Global Terrestrial Observing System reference site as well as for ecological, hydrological and remote sensing applications. It is situated $25 \mathrm{~km}$ south-west of Dresden (south-east Germany) on the northern slope of the Ore mountains. The main tower is located in the eastern part of the forest Tharandter Wald, and was constructed in 1990; the forest covers about 6000 ha. Two small unforested areas are located north and west of the main tower $\left(50^{\circ} 58^{\prime} \mathrm{N}\right.$, $13^{\circ} 34^{\prime} \mathrm{E}$ ); the slightly undulating terrain has an average height above sea level (a.s.l.) between $350 \mathrm{~m}$ and $400 \mathrm{~m}$. However, within a radius of $500 \mathrm{~m}$ the typical inclination is only about $2^{\circ}$ facing south with larger slopes in the south-east and north-east. In the western direction the terrain rises up to $422 \mathrm{~m}$ a.s.l. (for a comparison with other European spruce sites refer to Bernhofer et al. 2003; for a footprint and data quality assessment refer to Rebmann et al. 2005).

Norway spruce (Picea abies) is the dominant species of tree at this site, with an average canopy height of $29 \mathrm{~m}$ (year 2003) and a well-marked trunk space of about $12 \mathrm{~m}$. The understorey is very sparse; leaf area index is about 5.9 (measured in 2002, after thinning).

The climate is characterised by a mean annual air temperature of $7.7^{\circ} \mathrm{C}$ and a mean annual precipitation of $819 \mathrm{~mm}$; the mean temperature amplitude between summer and winter is $17.7 \mathrm{~K}$. Wind direction is predominantly from the south-west. The year 2003 was unusually dry and hot, and summer precipitation was $39 \%$ below the longtime average and the mean annual temperature was $1.3 \mathrm{~K}$ above the long-time average (source: data bank, Department of Meteorology, TU Dresden). For more detailed information about the site, refer to Grünwald (2002).

\subsection{Instrumentation and set-up}

In the description of the experimental set-up we concentrate on issues relevant to the present study. Three additional towers (P1, P2 and P3) were installed for the purpose 
Fig. 1 Scheme of experimental layout. ASTW denotes permanent main tower

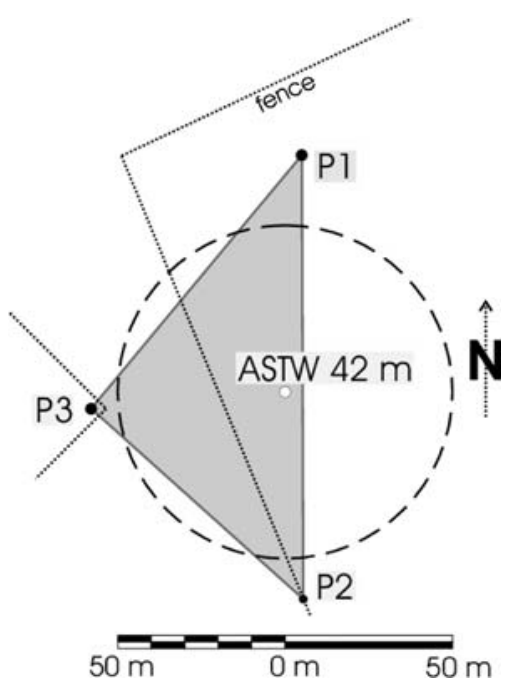

of MORE II and the permanent measurements were enhanced in order to estimate horizontal and vertical gradients (Fig. 1). The distances between P1 and P2, P1 and $\mathrm{P} 3, \mathrm{P} 2$ and $\mathrm{P} 3$ were $133 \mathrm{~m}, 99 \mathrm{~m}$ and $85 \mathrm{~m}$ respectively.

Observations used in the analysis are primarily the wind components $u$ (east), $v$ (north), $w$ (vertical) and sonic temperature $T_{s v}$, which were measured at $2.5 \mathrm{~m}$ above ground level (a.g.l.) (trunk space) and $30 \mathrm{~m}$ a.g.l. (above canopy) by sonic anemometers (METEK, USA-1, Germany) at each tower P1, P2 and P3 (Fig. 2). The sampling rate was $20 \mathrm{~Hz}$. Air temperature was measured by thermocouples (Campbell Sci., Logan/Utah, type E, US specification) with a probe diameter of $75 \mu \mathrm{m}$ at the same heights, and the sampling rate of the thermocouples was $1 \mathrm{~Hz}$. These thermocouples provided data for the calculation of the horizontal temperature gradients. At the main tower a vertical temperature profile was taken by identical thermocouples at a sampling rate of $1 \mathrm{~Hz}$ at heights a.g.l. of: $0.5,2,8,18,26,33$ and $40 \mathrm{~m}$; this profile was used for the estimation of storage change and vertical advection. From September until the end of the experiment measurements at $z=18 \mathrm{~m}$ were not available.

Sonic data were processed and stored on a single lap-top utilising LabView. Thermocouples were measured and stored with a CR23X data logger utilising a multiplexer (Campbell Sci., Logan/Utah), all referenced to the same temperature.

\section{Methods}

A period of 101 days from the beginning of July to October (day of year = DOY 185-285) was examined. To obtain a uniform basis for all calculations the data were adjusted for imperfect alignment of the sonics, coordinates were rotated around the $y$ - and $x$-axes, and sonic temperatures were converted to air temperatures.

The mean wind directions (all data) for the sonics at height $z=30 \mathrm{~m}$ (tower P1 and tower P2) clearly differed from those on the main tower $(z=42 \mathrm{~m})$, where only tower P3 showed good agreement. In order to obtain a uniform initial situation for the coordinate rotation, wind data for towers $\mathrm{P} 1$ and $\mathrm{P} 2$ were rotated around the vertical 
Fig. 2 Schematic

instrumentation of towers P1-P3. Grey circles with black cross denote measurements of wind components $u, v$, and $w$ (METEK USA-1) and of air temperature (Campbell Sci., Logan/Utah, type E, US specification). Only relevant instrumentation is shown

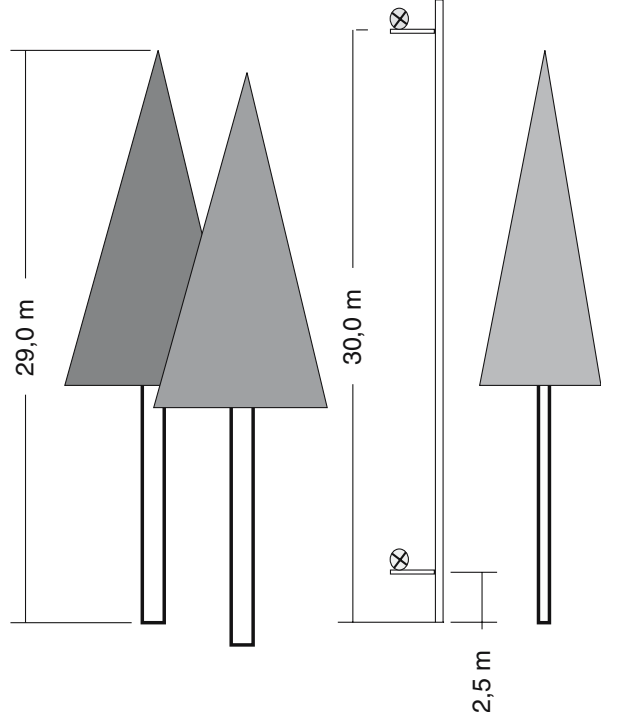

axis by $18^{\circ}$ and $35^{\circ}$, respectively. These angles were determined by using half-hourly data for the period DOY 185-285 where wind speed was greater than $4 \mathrm{~m} \mathrm{~s}^{-1}$.

No correction of the wind direction was applied to the sonics inside the canopy because no explicit rotation angle could be determined due to great scatter. Thus the sonic data in the trunk space are used without any alignment or adjustment.

Wind data were rotated around the $y$ - and $x$-axes using the planar fit after Wilczak et al. (2001); no rotation around the $z$-axis was made in order to preserve the orientation of the sonics. There exists some concern about the application of the planar fit in the trunk space (Wilczak et al. 2001), and so several rotation methods were tested inside the canopy. The main results changed only slightly, and for consistency the planar fit was chosen for the trunk space too. For further discussions please refer to the Appendix.

Measured turbulent heat fluxes were corrected according to Eq. (8) given in Schotanus et al. (1983). No correction was made for frequency loss. Above the forest the sensible heat flux or the buoyancy flux (covariance of ultrasonic wind speed and ultrasonic temperature) is only slightly damped and is often used as the reference for spectral corrections of the water vapour flux and $\mathrm{CO}_{2}$ flux (e.g. Eugster and Senn 1995; Grelle and Lindroth 1996; Bernhofer et al. 2003a). Below the canopy there exists little theoretical basis for any correction, and so we applied no correction for frequency loss of sensible heat flux.

The measurements reflect six corner points of an uneven prism, and gradients are assumed to behave linearly between points. The experimental set-up and the chosen methods for calculation of the advective terms are unable to capture horizontal gradient changes. Thus the gradients are supposed to be constant within the prism. Only linear gradients are assumed, which surely does not completely reflect the real conditions. 
3.1 The budget equation of sensible heat

In the following the budget of buoyancy flux is developed. The budget of sensible heat can be calculated by multiplying Eq. (1) below with air density and specific heat capacity. The source/sink strength term of the buoyancy flux in a control volume is determined by the changes in space and time:

$$
S(t, x, y, z)=\frac{\partial T}{\partial t}+\frac{\partial u T}{\partial x}+\frac{\partial v T}{\partial y}+\frac{\partial w T}{\partial z},
$$

where $x, y$ and $z$ form the coordinate system with $x$ directed east, $y$ north and $z$ normal to the surface; $u, v$ and $w$ are the wind components in this coordinate system, $t$ denotes time and $T$ temperature. Integrating over the height of the control volume, applying Reynolds averaging and Einstein summation according to Finnigan (1999) and Feigenwinter et al. (2004) results in:

$$
S(t, x, y, z)=\int_{0}^{z_{r}}\left(\frac{\partial \bar{T}}{\partial t}+\frac{\partial\left(\bar{u}_{j} \bar{T}\right)}{\partial x_{j}}+\frac{\left(\overline{u_{j}^{\prime} T^{\prime}}\right)}{\partial x_{j}}\right) \mathrm{d} z,
$$

where $x_{j}$ refers to the three directions in space $x, y$ and $z$ and $u_{j}$ to the corresponding wind components $u, v$ and $w$. Overbars denote time averages and primes departures of the instantaneous values from these time averages. Taking continuity into account $(\partial \bar{u} / \partial x+\partial \bar{v} / \partial y+\partial \bar{w} / \partial z=0)$ and assuming horizontally constant temperature gradients $\left(\partial^{2} \bar{T} / \partial x^{2}+\partial^{2} \bar{T} / \partial y^{2}=0\right)$ finally yields:

$$
\begin{gathered}
S(t, x, y, z)=\int_{0}^{z_{r}} \frac{\partial \bar{T}}{\partial t} \mathrm{~d} z+\int_{0}^{z_{r}} \frac{\partial\left(\overline{w^{\prime} T^{\prime}}\right)}{\partial z} \mathrm{~d} z+\int_{0}^{z_{r}} \bar{w} \frac{\partial \bar{T}}{\partial z} \mathrm{~d} z \\
+\int_{0}^{\mathrm{I}}\left(\bar{u} \frac{\partial \bar{T}}{\partial x}+\bar{v} \frac{\partial \bar{T}}{\partial y}\right) \mathrm{d} z+\int_{0}^{z_{r}}\left(\frac{\partial\left(\overline{u^{\prime} T^{\prime}}\right)}{\partial x}+\frac{\partial\left(\overline{v^{\prime} T^{\prime}}\right)}{\partial y}\right) \mathrm{III} z . \\
\operatorname{IV}
\end{gathered}
$$

Here, term I denotes storage change, term II vertical turbulent flux (mostly referred to as EC flux), term III vertical advection, term IV horizontal advection and term V horizontal turbulent flux divergence; $z_{r}$ is the height of the control volume. Positive fluxes refer to a transport out of the control volume (source), and negative fluxes indicate a transport into the control volume (sink). Positive storage change represents an additional source of heat and negative storage change a sink from the control volume.

\subsection{Estimation of vertical turbulent flux and of the storage change}

Calculation of the vertical turbulent flux followed the usual standard procedure, as can be found for instance in Aubinet et al. (2000). This procedure was applied to all towers. The vertical turbulent fluxes at height $z_{r}=30 \mathrm{~m}$ show a high correlation among the towers P1, P2, P3 with correlation coefficients $\geqslant 0.95$. Therefore the arithmetic mean of these vertical turbulent fluxes are taken as representative values. 


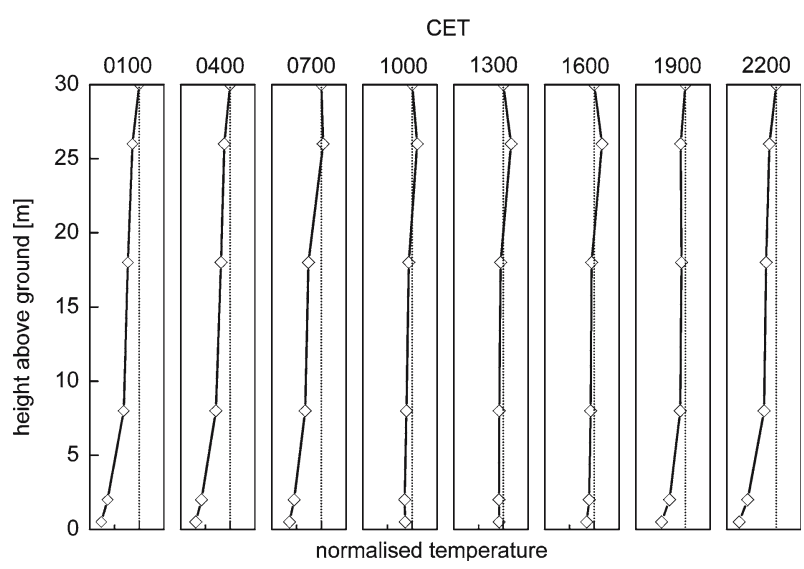

Fig. 3 Mean diurnal variation (DOY $185-285,1 \mathrm{~h}$ averages) of vertical temperature profiles (for further details see text). Temperatures were normalised with temperature at height $z=30 \mathrm{~m}$ and therefore have no dimension. Lower horizontal scale is omitted for clarity, the vertical dotted lines refer to a ratio of one. A value located to the right of this line is greater than one, while a value located to the left of this line is smaller than one, respectively. Time is CET

In order to estimate storage change, the vertical temperature profile at the main tower was assumed to be representative for the whole control volume. No measurement of air temperature at height $z_{r}=30 \mathrm{~m}$ was available at the main tower, and instead the arithmetic mean value of temperatures at P1, P2 and P3 at this height was used. Figure 3 shows the mean diurnal course of the vertical temperature profile calculated according to this assumption. It reflects a typical diurnal course of the temperature profile within and above the forest canopy; the stratification is stable at night and near neutral/ slightly unstable during daytime. A clear difference between trunk space and crown space can be seen. During the day highest temperatures are found in the upper crown space, which approximately coincides with the height of the highest leaf area density. At nighttime an inversion is visible at the height of maximum leaf area density. The inversion gradually covers the whole canopy during the night.

Storage changes were estimated in three different ways:

(I) using the vertical temperature profile at the main tower, which was considered to be representative for the whole control volume (Fig. 3);

(II) using only temperature measurements of P1, P2 and P3 at height $z=30 \mathrm{~m}$ and $z=2.5 \mathrm{~m}$;

(III) using only changes in temperature at height $z=30 \mathrm{~m}$.

All options of storage change yield similar results and follow the same diurnal course (see Sect. 4.2).

\subsection{Estimation of vertical advection and horizontal advection}

Vertical advection was calculated according to Lee (1998). Instead of the concentrations, which appear in the original equation, the temperature $\mathrm{T}_{r}$ at height $\mathrm{z}_{r}=30 \mathrm{~m}$ and the average temperature $\langle T\rangle$ between ground and height $z_{\mathrm{r}}$ were used. This yields: 


$$
\int_{0}^{z_{r}} \bar{w} \frac{\partial \bar{T}}{\partial z} \mathrm{~d} z=\overline{w_{r}}\left(\overline{T_{r}}-\langle T\rangle\right) .
$$

The averaged temperature of option I was calculated as follows:

$$
\langle T\rangle=\frac{1}{30}\left(8 \overline{T_{26 \mathrm{~m}}}+9 \overline{T_{18 \mathrm{~m}}}+8 \overline{T_{8 \mathrm{~m}}}+3.75 \overline{T_{2 \mathrm{~m}}}+1.25 \overline{T_{0.5 \mathrm{~m}}}\right)
$$

and the averaged temperature of option II was calculated as:

$$
\langle T\rangle=\frac{1}{30}\left(18 \overline{T_{30 \mathrm{~m}}}+12 \overline{T_{2.5 \mathrm{~m}}}\right),
$$

where the indices refer to the measurement heights. The weighting factor of each temperature represents the thickness of the layer for which the temperature is assumed to be representative. A vertical profile with higher resolution in space reproduces the real conditions better than a vertical profile consisting of only two measurements. Thus option I is likely to yield better results.

The same temperature profiles and scaling option I and II as for the computation of storage change (Sect. 3.2) were applied. The residual vertical wind speed after rotation by planar fit (Wilczak et al. 2001) was chosen to obtain the mean vertical velocity at each half hourly timestep.

Horizontal advection was calculated according to Feigenwinter et al. (2004) using the inclination of a plane to determine the horizontal gradients of air temperature. For the calculation of the horizontal air temperature gradients, air temperatures measured by thermocouples were used. In order to estimate the complete budget of sensible heat for the whole control volume (height of control volume $z_{\mathrm{r}}=30 \mathrm{~m}$ ), it was necessary to vertically extrapolate the horizontal advection and the horizontal eddy flux divergence, as there were only measurements at two heights $(2.5 \mathrm{~m}$ and $30 \mathrm{~m})$ available. We tested two different scaling options as described in the following section.

\subsection{Estimation of horizontal flux divergence}

In order to calculate the horizontal flux divergence, a similar procedure as for horizontal advection was chosen. However, in contrast to Feigenwinter et al. (2004), partial derivatives are computed. The horizontal turbulent fluxes $\overline{u^{\prime} T^{\prime}}$ and $\overline{v^{\prime} T^{\prime}}$ are components of a vector,

$$
\vec{H}=\left[\overline{\frac{u^{\prime} T^{\prime}}{v^{\prime} T^{\prime}}}\right] .
$$

All these vectors form a vector field, whose divergence gives the horizontal flux divergence of sensible heat,

$$
\operatorname{div} \mathbf{H}=\rho c_{p}\left(\frac{\partial \overline{u^{\prime} T^{\prime}}}{\partial x}+\frac{\partial \overline{v^{\prime} T^{\prime}}}{\partial y}\right),
$$

where $\rho$ is density of air and $c_{p}$ specific heat capacity of air.

The partial derivatives were computed using the equation of a plane $\mathrm{A} x+\mathrm{B} y+$ $\mathrm{C} z+\mathrm{D}=0$. The plane is defined by three points, which are given by the experimental set up ( $x$ - and $y$-coordinates); the $z$-coordinate refers to $\overline{u^{\prime} T^{\prime}}$ or $\overline{v^{\prime} T^{\prime}}$, respectively. 
Two planes were computed for every half hour, one for $\overline{u^{\prime} T^{\prime}}$ to obtain $\frac{\partial \overline{u^{\prime} T^{\prime}}}{\partial x}$ and one for $\overline{v^{\prime} T^{\prime}}$ to obtain $\frac{\partial \overline{v^{\prime} T^{\prime}}}{\partial y}$ (see Appendix for more details).

In order to obtain a complete budget, the following scaling options were used:

(A) The "active surface" of the canopy was used to identify above canopy advection and inside canopy advection. Measurements at height $z=30 \mathrm{~m}$ were taken to be representative of a layer with a thickness of $\left(z_{r}-z_{d}\right)$ where $z_{\mathrm{r}}$ is the height of the control volume and $z_{d}$ is the displacement height. Measurements at height $z=2.5 \mathrm{~m}$ were taken to be representative of a layer with thickness $z_{d}=20.6 \mathrm{~m}$ (Queck 2004).

(B) The volume was split into "crown space" and "trunk space". Measurements at height $z=30 \mathrm{~m}$ were considered to be representative of a layer between $12 \mathrm{~m}$ and $30 \mathrm{~m}$ (the crown space mean height $=18 \mathrm{~m}$ ) and measurements at height $z=2.5 \mathrm{~m}$ for a layer of depth $12 \mathrm{~m}$ (trunk space).

It is clear that these options can only show the range of the possible contributions of the horizontal flux divergence term. Option A reflects meteorological wisdom, since the height of the zero plane displacement separates two wind regimes (above and below canopy). Option B takes canopy structure into account and the fact that wind speeds are generally low in the crown space. However, it should be kept in mind that scaling is a source of systematic errors. This applies to horizontal advection too.

\section{Results}

\subsection{Storage change}

Figure 4 shows the ensemble mean from DOY 185 through 285 (4 July through 12 October) of the different calculation options (Section 3.1) of storage change. All options of storage change follow the same diurnal course, and indicate a gain of sensible heat between early morning and late midday and a loss during the rest of the day. The slope of the linear regression between the different options of calculation has a minimal value of 0.93 (between option I and option III). Obviously, the difference between the calculation methods using one, two or 6 and 5 levels is not significant. This agrees with Mellmann (1998). However, a slight loss of information is observed with a decreasing number of considered levels. It is very likely that the storage change maximum and minimum are underestimated when using fewer levels.

\subsection{Vertical advection and horizontal advection}

Vertical advection was estimated using options I and II (Sect. 3.2), and again, the diurnal courses (ensemble mean) of the two options are similar (Fig. 5). Calculation with only two levels (option II) obviously underestimates the maximum and the minimum. During the night the flux is directed towards the control volume. In the morning (0600-1000) the value is positive, and at noon and in the afternoon (1200-1800) it is close to zero. At this time the atmosphere is well mixed and differences in temperature between the different levels become smaller with less vertical advection.

Horizontal advection was calculated for each level as described in Sect. 3.3 and scaled afterwards (Sect. 3.4). Horizontal advection was higher at night than during the day (Fig. 6). The mean diurnal course and the time of peaks for both scaling 


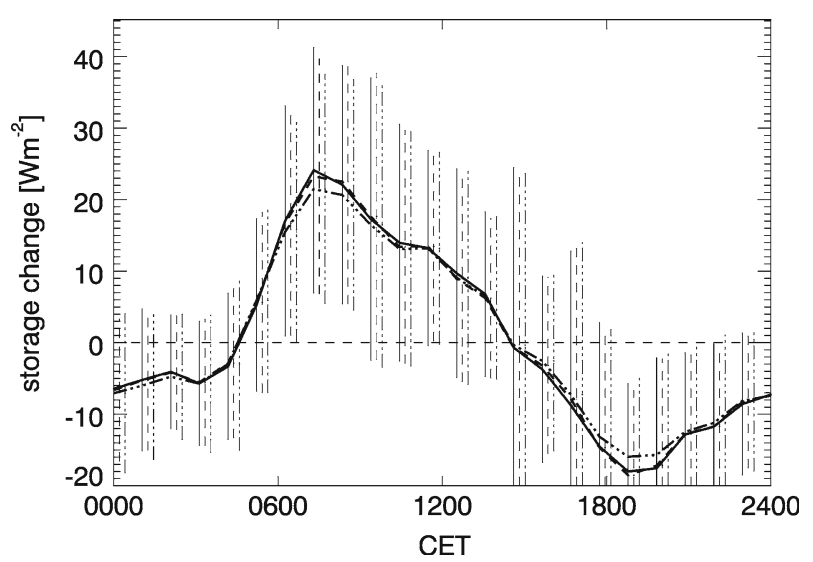

Fig. 4 Ensemble means of different calculation options of storage change of sensible heat with standard error bars (DOY 185-285, 1-h averages). Option I (solid line), option II (dashed line), option III (dashed double dotted line). Standard error bars refer to the same symbols

Fig. 5 Ensemble means of different calculation options of vertical advection of sensible heat with standard error bars DOY 185-285, 1-h averages. Option I (solid line), option II (dashed line). Error bars refer to the same symbols

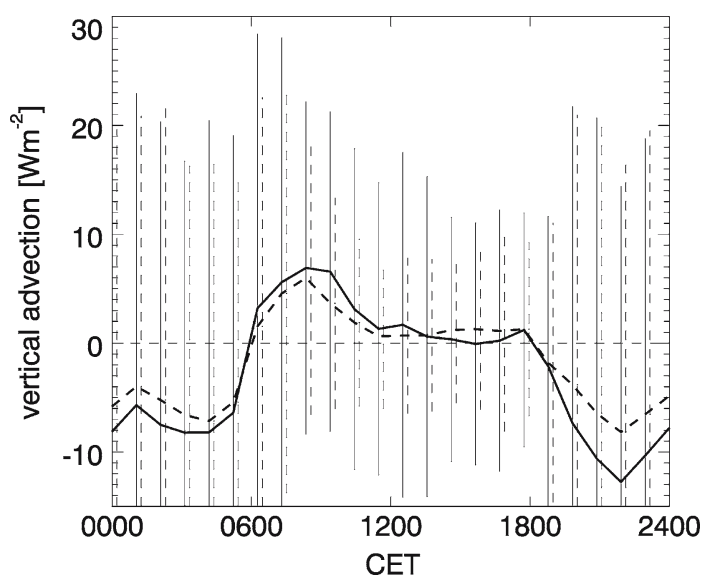

options are similar. However, there is a clear difference between the two options (Fig. 6). In general, the wind speed above the canopy is higher than within the canopy for both day and night, while horizontal temperature gradients (Fig. 7) are slightly higher in the trunk space compared to above the canopy at night. Large horizontal temperature gradients were not to be expected, since the mean differences in temperature between the towers range between $0.002 \mathrm{~K}$ and $0.2 \mathrm{~K}$ and the distances between the towers is about $100 \mathrm{~m}$ (see Sect. 2.2).

The lower measurement level contributes more significantly to horizontal advection in option A compared to option B. Since at night option A is more negative than option B, the larger gradients overcompensate for the smaller wind speed in the trunk space. Between 0400 and 0600 the two options yield different signs for the horizontal advection, and shows how scaling may lead to different magnitudes of a budget term. However, the temperature gradients are very small, and may be smaller than the accuracy of measurement despite the large statistical sample, introducing considerable uncertainty into the flux budget. 
Fig. 6 Diurnal courses of different calculation options of horizontal advection of sensible heat with standard error bars (DOY 185-285, 1-h averages). Option A (solid line), option B (dashed line). Error bars refer to the same symbols
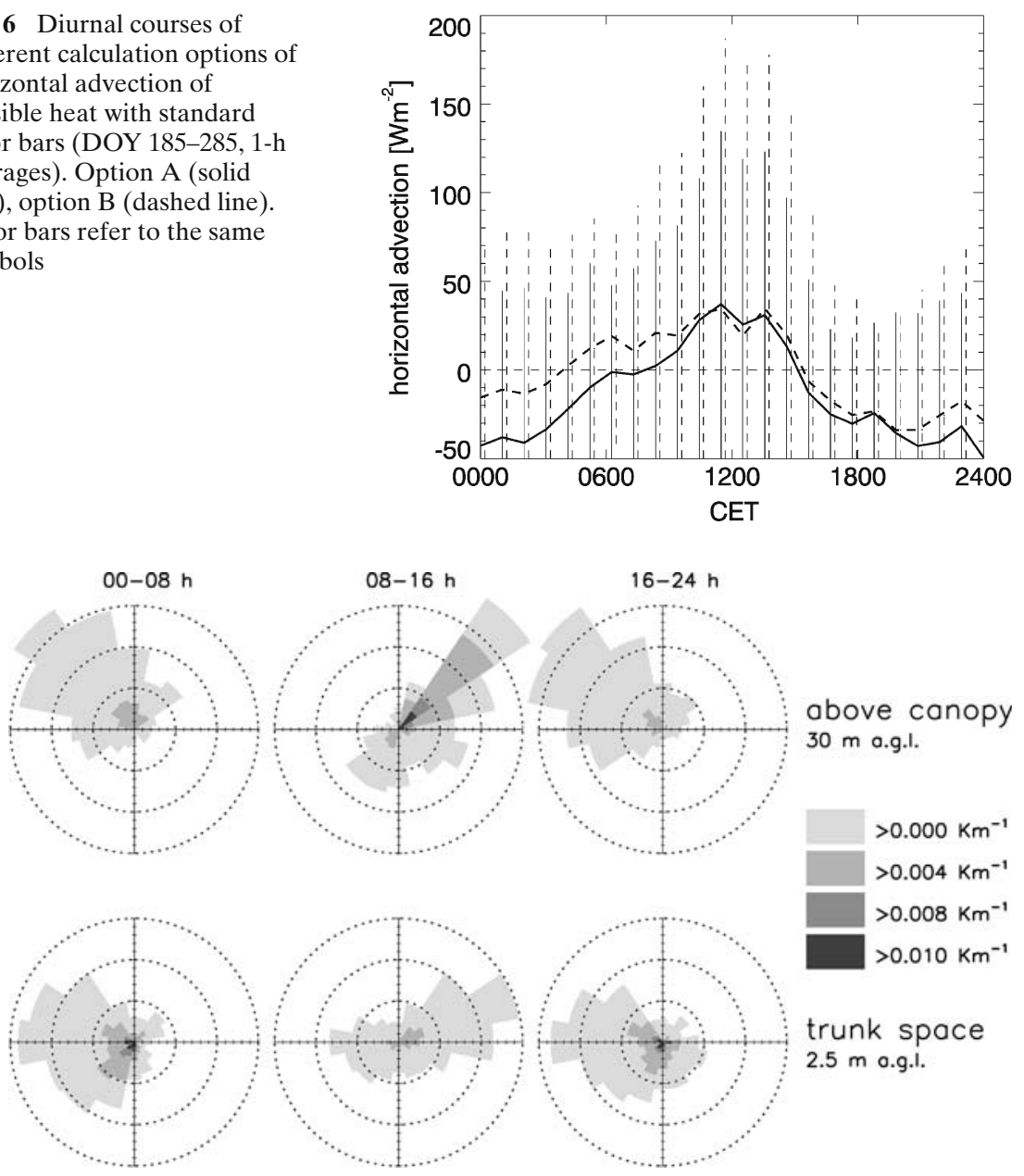

above canopy

$30 \mathrm{~m}$ o.g.l.

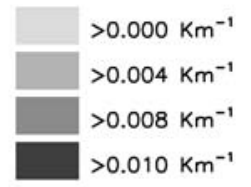

trunk space

$2.5 \mathrm{~m}$ o.g.I.

Fig. 7 Diurnal gradients separated in 16 direction classes at the top of the canopy (top) and in the trunk space (bottom), pointing from low to high temperatures. Outer circles denote $15 \%$ of total values

$\mathrm{CO}_{2}$ advection measurements have shown that horizontal differences of $\mathrm{CO}_{2}$ decrease rapidly with height (e.g. Feigenwinter et al. 2004). This may also apply to the horizontal differences of air temperatures. Therefore, the horizontal advection might be overestimated by assuming constant gradients over the two parts of the profile.

Comparing mean diurnal courses of horizontal advection and vertical advection shows that heat flux by vertical advection is smaller, at least for this dataset, and indicates that the transport with the mean wind in the horizontal direction cannot be neglected at this site.

\subsection{Horizontal flux divergence}

Horizontal flux divergence was determined according to Sect. 3.4. There is a weak diurnal variation in the ensemble mean for both scaling options A and B (Fig. 8). 


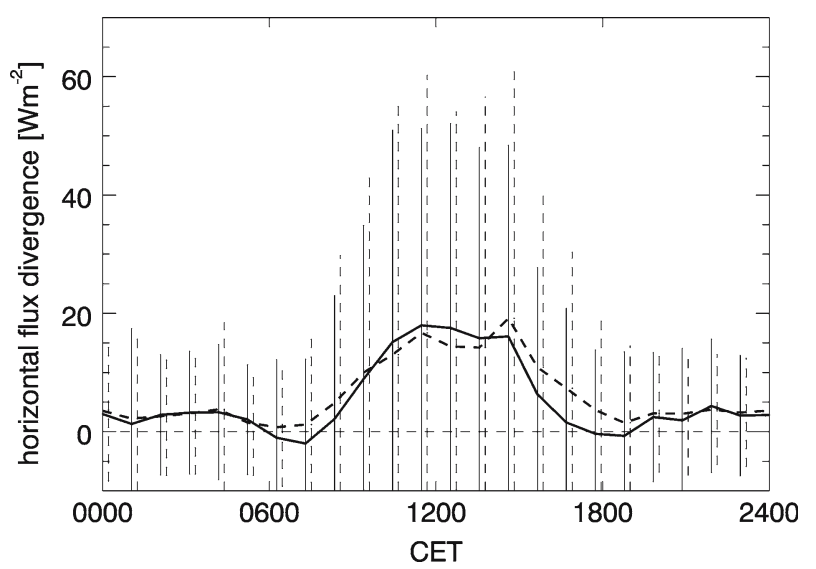

Fig. 8 Mean diurnal courses of different calculation options of horizontal flux divergence (DOY 185-285, 1-h averages). Option A (solid line), option B (dashed line). Error bars refer to same symbols

During the day the horizontal flux divergence has largest values, but at night, when storage and advection processes dominate, the horizontal flux divergence of sensible heat is around zero. For both options this term can be positive or negative, i.e. it acts as a sink or a source. However, on average the term is positive.

Figure 9 depicts the behaviour of the horizontal turbulent flux divergence in relation to atmospheric stability. It shows highest values under unstable conditions and smaller values under stable conditions with suppressed turbulence. The horizontal flux divergence seems to be insignificant under neutral conditions. Horizontal flux divergence is relatively high under very unstable conditions, but absolute values are small compared to other components of the sensible heat budget. This points to effects of inhomogeneity, since for a homogeneous site during free convection $(z / L \ll-1)$ there should be no preferred $\mathrm{x}$-direction and therefore no correlation between fluctuations of $u$ and $T$ (Wyngaard et al. 1971). Wyngaard et al. (1971) refer to the site of the Kansas field program in 1968, which was a flat uniform site (Kaimal et al. 1972).

The horizontal flux divergence shows a weak dependence on friction velocity $u_{*}$ and the pattern is not very clear (Fig. 10). The divergence rises with increasing friction velocity above the typical threshold of $0.3 \mathrm{~m} \mathrm{~s}^{-1}$ for this site. It tends to decline when $u_{*}$ becomes $>0.7 \mathrm{~m} \mathrm{~s}^{-1}$. A second increase (below the typical $u_{*}$ threshold) may be due to a smaller bin size. An increase in horizontal flux divergence was found with rising net radiation (not shown). An examination of horizontal flux divergence in relation to wind direction did not show much variation due to the little variation of wind direction during the experiment (south-westerly winds dominated). However, highest values of horizontal flux divergence were found with the wind from the south-west.

We would like to stress that the result of near-zero eddy flux divergence is probably site and measurement period specific (as the heterogeneity of the Tharandt site is limited and basically only one wind direction is covered). 


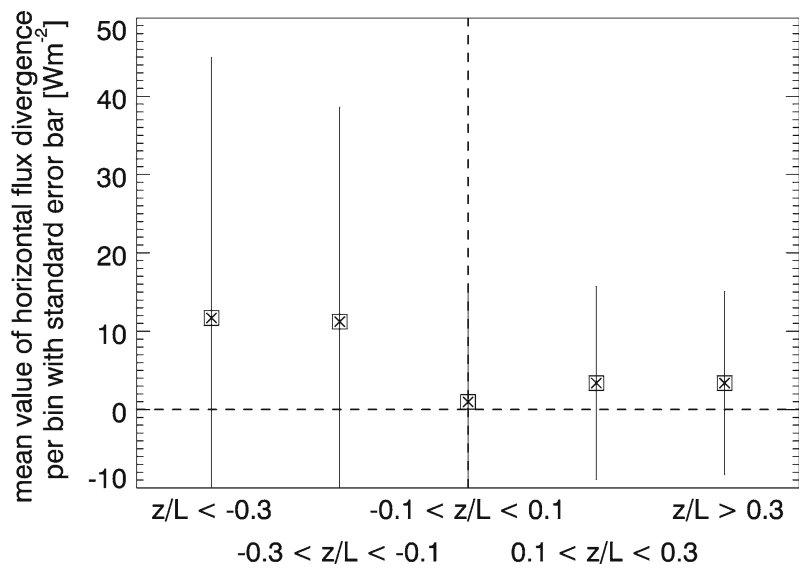

Fig. 9 Horizontal flux divergence in relation to atmospheric stability. Horizontal flux divergence was scaled with option A

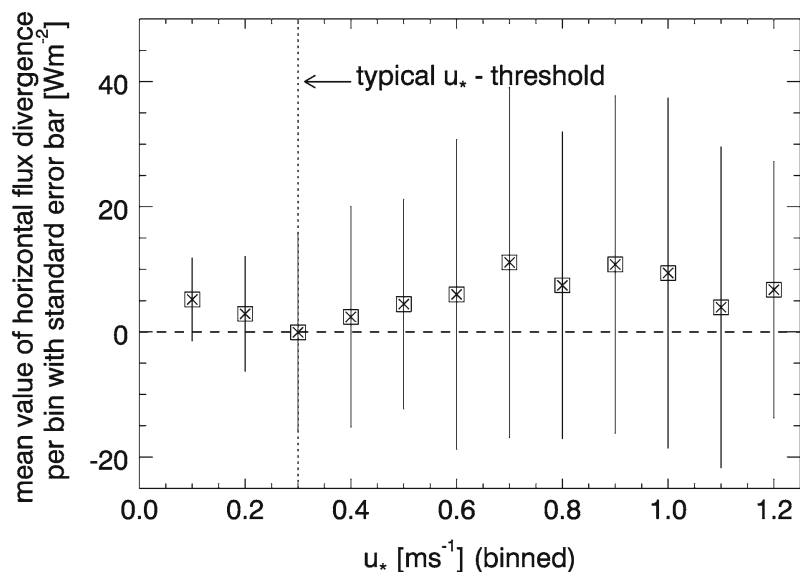

Fig. 10 Horizontal flux divergence in relation to friction velocity. Horizontal flux divergence was scaled with option A

\subsection{Mean values of budget terms}

The mean values of the different terms of the budget together with their different scaling options are listed in Tables 1 and 2 . They are roughly separated into nighttime and morning transition period (0000-0800), daytime (0800-1600) and the evening transition period (1600-2400). Naturally, the times of sunrise and sunset change significantly over a period of 101 days. Comparing the mean values for storage change reveals that there is not much difference between the three computation methods. Storage change appears to be relatively insensitive to a higher spatial resolution of the vertical temperature profile. Additionally, this might indicate that there is a relatively good coupling between trunk space and the tower top, and partly supported by Feigenwinter et al. (2004) who observed no nighttime cold air drainage at this site. The robustness of the calculation to variable spatial resolution of the vertical temperature 
Table 1 Mean values (DOY 185-285) of sensible heat flux (vertical turbulent flux and storage change) in $\mathrm{W} \mathrm{m}^{-2}$

\begin{tabular}{lccrr}
\hline Period & EC flux & \multicolumn{2}{l}{ Storage change } \\
\cline { 3 - 5 } & & Option I & Option II & Option III \\
\hline $0000-0800$ & -13.0 & 2.9 & 2.8 & 2.3 \\
$0800-1600$ & 173.3 & 9.8 & 9.7 & 9.4 \\
$1600-2400$ & -7.0 & -12.6 & -12.5 & -11.6 \\
\hline
\end{tabular}

Table 2 Mean values (DOY 185-285) of sensible heat flux (vertical and horizontal advection and horizontal flux divergence) in $\mathrm{W} \mathrm{m}^{-2}$

\begin{tabular}{|c|c|c|c|c|c|c|}
\hline \multirow[t]{2}{*}{ Period } & \multicolumn{2}{|c|}{ Vertical advection } & \multicolumn{2}{|c|}{ Horizontal advection } & \multicolumn{2}{|c|}{ Horizontal flux divergence } \\
\hline & Option I & Option II & Option A & Option B & Option A & Option B \\
\hline 0000-0800 & -4.3 & -3.4 & -23.9 & -0.5 & 1.6 & 2.3 \\
\hline 0800-1600 & 2.5 & 2.0 & 17.0 & 21.8 & 13.9 & 13.7 \\
\hline $1600-2400$ & -6.0 & -3.5 & -35.0 & -25.7 & 1.8 & 3.7 \\
\hline
\end{tabular}

profile applies to a minor degree also to the results of vertical advection. However, the difference between both options is clearer. Option B results in a smaller flux and might underestimate the vertical advection.

There is a significant difference in mean sums between the two scaling options for horizontal advection. While option A emphasises the measurements in the trunk space, option B emphasises the measurement just above the canopy at $z=30 \mathrm{~m}$. Additionally, during the night the fluxes at $z=2.5 \mathrm{~m}$ and $z=30 \mathrm{~m}$ are of opposite direction, due to positive temperature gradients and a higher wind speed in the $y$-direction (north) at $z=30 \mathrm{~m}$. Option B is probably not suitable for scaling in this case, as the mean sum at night is almost zero. This is probably not reasonable as we expect a significant contribution of the non-turbulent flux during night. In comparison to vertical advection the transport of sensible heat by horizontal advection is large. At night horizontal advection exceeds the vertical turbulent flux.

The horizontal flux divergence has the smallest mean values of all the terms in the budget. The divergence in relation to EC flux (vertical turbulent flux) and to horizontal advection (calculated with option A) yields values as noted in Table 3. Results over the whole time period exceed slightly the limits as stated by Staebler and Fitzjarrald (2004), who found that the horizontal eddy flux divergence was usually not more than $10 \%$ of the EC flux, and less than $30 \%$ of the mean horizontal advection. These limits are exceeded by options A and B for the mean values of the whole period. Option B may represent an upper limit.

Table 3 Percentage (DOY 185-285, half hourly values) of the different options of the horizontal flux divergence in relation to EC flux and horizontal advection (option A)

\begin{tabular}{|c|c|c|c|c|}
\hline & \multicolumn{2}{|c|}{ (Divergence/EC flux) } & \multicolumn{2}{|c|}{ (Divergence/Horizontal advection) } \\
\hline & Option A & Option B & Option A & Option B \\
\hline Whole period & 11 & 13 & 41 & 49 \\
\hline
\end{tabular}


It should be noted that values of the horizontal flux divergence carry a great uncertainty, since they are very small and characterised by large scatter. Especially for this flux the applied scaling options remain questionable, since little is known about this term and its behaviour along vertically and horizontally changing conditions.

\subsection{Effect on the whole budget}

To evaluate the importance of the vertical turbulent flux, storage change, vertical advection, horizontal advection, and horizontal flux divergence, we compared their magnitude in relation to available energy (sum of net radiation plus ground heat flux). The data were binned into groups of $4 \mathrm{~h}$ according to daytime. For each bin the mean value of the regarded term divided by available energy was calculated (Fig. 11). The vertical turbulent flux is important over the whole day, although its importance clearly decreases in late night/early morning. During this period the importance of storage change increases. Aubinet et al. (2005) found an increase in storages fluxes of $\mathrm{CO}_{2}$ at different sites during this part of the night, and reasoned this might be due to an increase of advection in the second part of the night. Figure 11 shows that non-turbulent horizontal advection has one of the biggest magnitudes in relation to

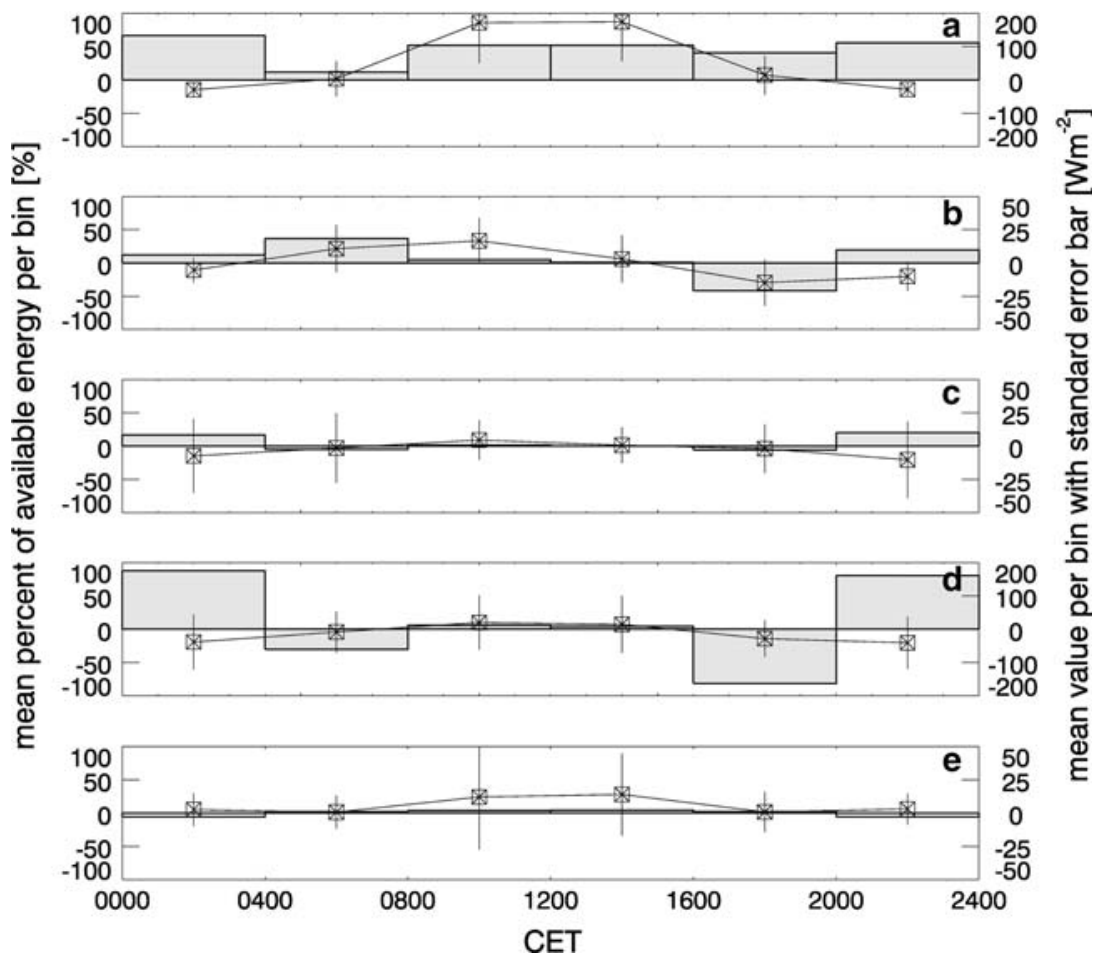

Fig. 11 Relative magnitude of each budget term of sensible heat in relation to available energy per bin (left $y$-axis and grey columns). Mean value per bin with standard error bar in $\mathrm{W} \mathrm{m}^{-2}$ (right $y$-axis). Data were binned, bin size is $4 \mathrm{~h}$. From top to bottom: a: vertical turbulent flux, b: storage change, $\mathbf{c}$ vertical advective flux, $\mathbf{d}$ : horizontal advective flux, e: horizontal flux divergence. Please note different scales of the right y-axes 
the other fluxes during this time. However, there is no increase in this flux during the second part of the night. During daytime storage change is less important due to the well-mixed profile.

A weak diurnal variation of vertical advection can be seen and, in relative magnitude, it has nearly no importance during daytime and only a limited importance at night. At night, the atmosphere is more stable and both horizontal and vertical temperature gradients become larger (see Sect. 4.2) with advective processes becoming more important. Horizontal advection plays a very important role at night, but is clearly less important during the day, when the atmosphere is well mixed. At night the ratio to available energy is large, since available energy is small. The diurnal variation is also much stronger than for vertical advection.

The horizontal flux divergence has no significant magnitude in relation to available energy during the whole day. There is a very slight increase during nighttime only. Even during daytime, this flux has little or no importance whereas the vertical turbulent flux increases much stronger. These findings and the results discussed in Sects. 4.3 and 4.4 support the hypothesis that neglecting the horizontal flux divergence does not introduce a significant error into the energy budget. Nevertheless, we found that including horizontal flux divergence might change the budget of sensible heat slightly, as shown in the discussion below.

Figure 12 shows an overview of the different budget terms for sensible heat. Storage change and vertical advection were estimated with option I, and horizontal advection

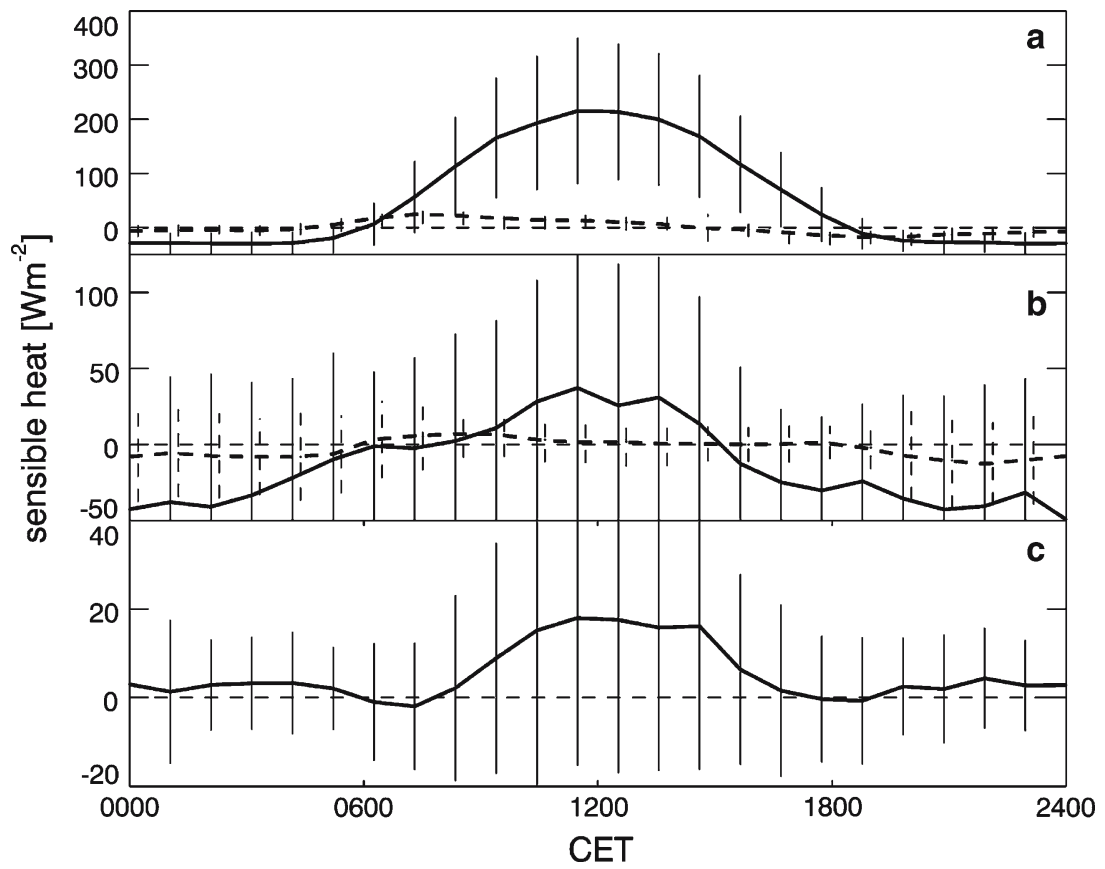

Fig. 12 Mean diurnal variations (hourly mean) of the budget terms of sensible heat in $\mathrm{W} \mathrm{m}^{-2}$ with standard error bars. From top to bottom: a: vertical turbulent flux (solid line), storage change (dashed line), b: vertical advective flux (dashed line), horizontal advective flux (solid line), c: horizontal flux divergence 
Table 4 Mean values (DOY 185-285) of sensible heat in $\mathrm{W} \mathrm{m}^{-2}$

\begin{tabular}{lrrll}
\hline Period & All terms & $\begin{array}{l}\text { EC flux }+ \text { storage } \\
\text { change }\end{array}$ & $\begin{array}{l}\text { Vertical + horizontal } \\
\text { advection }\end{array}$ & $\begin{array}{l}\text { Advective terms + horizontal } \\
\text { turbulent flux divergence }\end{array}$ \\
\hline $0000-0800$ & -36.7 & -10.1 & -28.2 & -26.6 \\
$0800-1600$ & 215.6 & 183.1 & 19.5 & 32.5 \\
$1600-2400$ & -58.7 & -19.6 & -41.0 & -39.1 \\
$0000-2400$ & 42.0 & 52.6 & -16.2 & -10.7
\end{tabular}

Storage change and vertical advection are estimated with option I. Horizontal advection and horizontal flux divergence are estimated with option A

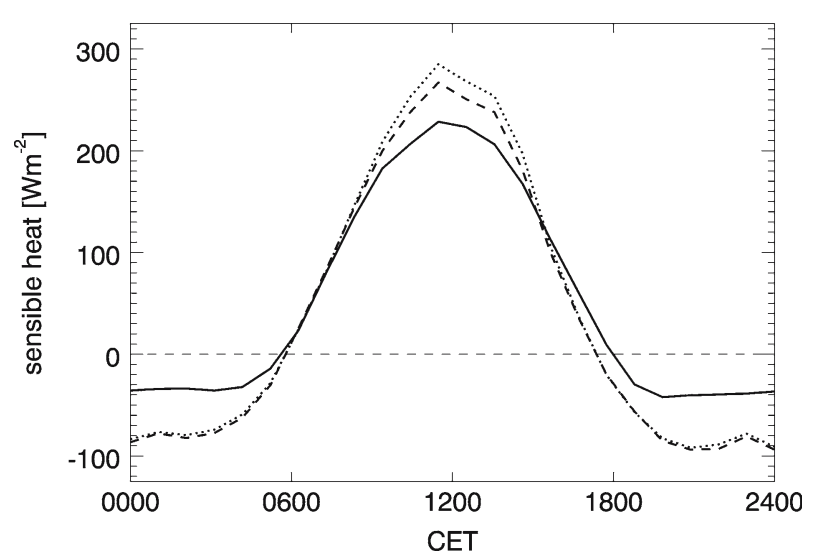

Fig. 13 Change of daily amplitude of sensible heat if advective fluxes are included. Vertical turbulent flux plus storage change (solid line), vertical turbulent flux plus storage change plus vertical and horizontal advection (dashed line), all terms including horizontal flux divergence (dotted line)

and horizontal flux divergence were scaled with option A. Vertical advection and horizontal advection have the same direction and do not cancel each other; these advective terms and the horizontal flux divergence show large scatter. This does not necessarily represent an error, but also represents the variability of the fluxes due to changing meteorological conditions.

Table 4 gives mean budgets for options shown in Fig. 12. For this combination of options, the mean value of the commonly measured fluxes (EC flux plus storage change) is reduced by $30 \%$, if horizontal and vertical advection terms are taken into account (whole day). If the horizontal flux divergence is regarded as well, the total sum (EC flux plus storage change plus horizontal and vertical advection) is increased by $10 \%$ (option A) and $5 \%$ (option B), respectively. This applies to all other combinations of options (option B of horizontal advection is neglected). However, a separate inspection of daytime and nighttime fluxes reveals an increase of downward fluxes at nighttime and during the transition period of about $200 \%$, while the daytime upward flux is increased by about $15 \%$. The daily amplitude is enlarged (Fig. 13). Advective fluxes obviously improve typically poor nighttime energy budget closure and, assuming similarity between temperature and $\mathrm{CO}_{2}$ concentration, might change ecosystem respiration fluxes considerably. 


\section{Conclusion and outlook}

Albeit the advective fluxes and the divergence show large scatter and scaling incorporates a good deal of uncertainty, our results confirm that flux towers should be used to test for the relative importance of advective fluxes. Neglect of these fluxes might lead to incorrect budgets. We tested various scaling options given the limited spatial resolution available. Storage change and vertical advection are not very sensitive to the scaling options applied. For the turbulent horizontal flux divergence it is still difficult to evaluate its importance at all. However, the budget of sensible heat is slightly changed if the horizontal flux divergence is included, but in relation to available energy this flux had rather no importance at this site and during the period of investigation.

The results have consequences for the problem of energy balance closure and for the nighttime $\mathrm{CO}_{2}$ flux. The budget of sensible heat changes if advective fluxes and horizontal flux divergence are taken into account. Advective fluxes would decrease this lack of closure on an hourly basis, but increase it for daily sums, whilst horizontal flux divergence might slightly reduce typical closure problems in the study presented here. Proceeding from the assumption that the sensible heat flux and the $\mathrm{CO}_{2}$ flux are generally of opposite direction, it can be stated that the carbon sink would be reduced by advective terms in this case. This would be partly compensated by horizontal flux divergence.

In order to obtain a better understanding of energy and mass fluxes at sites with horizontal heterogeneity or sloping terrain, more measurements are needed at different levels within and above the canopy in order to reduce uncertainties in the advective fluxes and the horizontal flux divergence. This would also help to reduce the uncertainty regarding the choice of scaling heights, as shown here.

Acknowledgements This research was supported by the Bundesministerium für Bildung und Forschung in the frame of the AFO 2000 project VERTIKO (Contract \#07ATF37-UBAS) and by CARBOEUROFLUX of the European Commission (Contract EVK2-1999-00229). We acknowledge Dr. Barbara Köstner and Dr. Thomas Grünwald for their assistance. Special thanks go to Uwe Eichelmann, Dr. Ronald Queck and Dr. Roland Vogt for their support before, during and after the campaign. The authors are also grateful to all reviewers and we appreciate the chance to improve the manuscript accordingly.

\section{Appendix}

\section{A1 Application of planar fit}

Use of the planar fit method is regarded as insufficient within the trunk space. However, for consistency with the above-canopy treatment we applied this method in the trunk space too. To illustrate the sensitivity to that treatment the turbulent fluxes $\overline{u^{\prime} T^{\prime}}, \overline{v^{\prime} T^{\prime}}$ and $\overline{w^{\prime} T^{\prime}}$, rotated with the common double rotation, are compared with the planar fit (now rotated into the mean wind direction). Good agreement was found for $\overline{u^{\prime} T^{\prime}}$ and $\overline{v^{\prime} T^{\prime}}$ above the canopy as well as in the trunk space, with regression slopes that are between 0.99 and 1.04. The regression slopes for $\overline{w^{\prime} T^{\prime}}$ (above canopy) were between 0.9 and 1.07. The wind directions were almost constantly south-west above the canopy as well as within the trunk space. This may be one reason for this good agreement. Thus we concluded that in this case an application of planar fit within 
Table 5 Mean values (DOY 185-285) of horizontal flux divergence and non-turbulent horizontal advection in $\mathrm{W} \mathrm{m}^{-2}$

\begin{tabular}{lcc}
\hline Period & Horizontal advection & $\begin{array}{l}\text { Horizontal flux divergence } \\
\text { Option A }\end{array}$ \\
\hline $0000-0800$ & Option A & $-0.8(1.6)$ \\
$0800-1600$ & $-48.2(-23.9)$ & $7.6(13.9)$ \\
$1600-2400$ & $37.4(17.0)$ & $-1.8(1.8)$ \\
\hline
\end{tabular}

Both fluxes are estimated with option A. Wind components above the canopy were rotated using planar fit (only around the $y$ - and $x$-axis). Wind components within the canopy were rotated using double rotation. The numbers in brackets give the results using planar fit as applied in the main text

the canopy may be justified to avoid an inconsistent treatment above and below the canopy.

We also tested the application of the double rotation method in the trunk space to compute eddy flux divergence. The mean diurnal courses of the horizontal eddy flux divergence and the non-turbulent horizontal advection were not changed. However, when applying double rotation non-turbulent advection increased during the night and horizontal eddy flux divergence was found to be mostly negative at night (Appendix Table 5). The influence of scaling becomes obvious, since the mean values for option B (not shown in Appendix Table 5) are always positive. The impact of the horizontal eddy flux divergence on the sensible heat budget remained negligible, while non-turbulent horizontal advection became even more important.

\section{A2 Horizontal flux divergence}

The horizontal turbulent fluxes $\overline{u^{\prime} T^{\prime}}$ and $\overline{v^{\prime} T^{\prime}}$ are components of a vector of kinematic heat $\vec{H}_{\text {kin }}$,

$$
\vec{H}_{\text {kin }}=\left[\begin{array}{l}
\overline{u^{\prime} T^{\prime}} \\
\overline{v^{\prime} T^{\prime}}
\end{array}\right],
$$

and form a vector field; it is possible to compute the divergence of this field. A non-zero divergence will indicate whether there is a source or sink of the considered variable. The divergence of an arbitrary vector field $\vec{F}$ is given by:

$$
\operatorname{div} \vec{F}=\frac{\partial F_{x}}{\partial x}+\frac{\partial F_{y}}{\partial y}+\frac{\partial F_{z}}{\partial z} .
$$

Restricting this to the two-dimensional case on a plane and to the examined horizontal turbulent fluxes results in:

$$
\operatorname{div} \mathbf{H}_{\mathrm{kin}}=\frac{\partial \overline{u^{\prime} T^{\prime}}}{\partial x}+\frac{\partial \overline{v^{\prime} T^{\prime}}}{\partial y},
$$

where the dimension is $\mathrm{Ks}^{-1}$.

The partial derivatives are computed with the equation of a plane

$$
A x+B y+C z+D=0,
$$

i.e. a similar procedure was chosen like for the estimation of horizontal gradients after Feigenwinter et al. (2004). Two planes are computed, one with $\overline{u^{\prime} T^{\prime}}$ and one with $\overline{v^{\prime} T^{\prime}}$. 
The planes are defined by three points (three towers P1, P2, P3), which are given by the experimental set-up ( $x$ - and $y$-coordinates, positions of the towers) and $\overline{u^{\prime} T^{\prime}}$ and $\overline{v^{\prime} T^{\prime}}$, respectively ( $z$-coordinate). Two planes are calculated, one for $\overline{u^{\prime} T^{\prime}}$ to obtain $\frac{\partial \overline{u^{\prime} T^{\prime}}}{\partial x}$ and one for $\overline{v^{\prime} T^{\prime}}$ to obtain $\frac{\partial \overline{v^{\prime} T^{\prime}}}{\partial y}$.

Using matrix notation gives:

$$
\left|\begin{array}{llll}
x & x_{1} & x_{2} & x_{3} \\
y & y_{1} & y_{2} & y_{3} \\
z & z_{1} & z_{2} & z_{3} \\
1 & 1 & 1 & 1
\end{array}\right|=0
$$

with axis intercepts as follows:

$$
\begin{aligned}
& A=y_{2} z_{3}+y_{3} z_{1}+y_{1} z_{2}-y_{3} z_{2}-y_{1} z_{3}-y_{2} z_{1}, \\
& B=x_{3} z_{2}+x_{1} z_{3}+x_{2} z_{1}-x_{2} z_{3}-x_{3} z_{1}-x_{1} z_{2}, \\
& C=x_{2} y_{3}+x_{3} y_{1}+x_{1} y_{2}-x_{3} y_{2}-x_{1} y_{3}-x_{2} y_{1}=\text { const. } \\
& D=x_{1} y_{3} z_{2}+x_{2} y_{1} z_{3}+x_{3} y_{2} z_{1}-x_{1} y_{2} z_{3}-x_{3} y_{1} z_{2}-x_{2} y_{3} z_{1} .
\end{aligned}
$$

Re-arranging the equation of the plane after $z$ and differentiating for $x$ and $y$, respectively, to obtain partial derivatives yields,

$$
\begin{gathered}
\frac{\partial z}{\partial x}=-\frac{A}{C}, \\
\frac{\partial z}{\partial y}=-\frac{B}{C} .
\end{gathered}
$$

As $z$ stands for $\overline{u^{\prime} T^{\prime}}$ and $\overline{v^{\prime} T^{\prime}}$, respectively we can write:

$$
\begin{gathered}
\frac{\partial \overline{u^{\prime} T^{\prime}}}{\partial x}=-\frac{A}{C}, \\
\frac{\partial \overline{v^{\prime} T^{\prime}}}{\partial y}=-\frac{B}{C},
\end{gathered}
$$

where the dimension is $\mathrm{Ks}^{-1}$. Multiplying with the density of air and specific heat capacity yields the divergence of sensible heat.

Note that the $x$ and $y$ coordinates are constant and that a linear change of horizontal turbulent fluxes is implicitly assumed.

\section{A3 Accuracy of measurement}

All the sonic anemometers used in our experiments were tested in a field experiment in Aesch (Switzerland). The measured horizontal wind components $u$ and $v$ showed good agreement with derived slopes that were approximately unity (1.01-1.02) and a correlation coefficient of 0.99 . The mean difference (among the sonic measurements above the canopy) of the wind components $u$ and $v$ had an absolute value of 0.0074 and $0.0079 \mathrm{~m} \mathrm{~s}^{-1}$, respectively, equal to the accuracy given by the manufacturer $\left( \pm 0.01 \mathrm{~m} \mathrm{~s}^{-1}\right)$.

The turbulent buoyancy fluxes derived on the basis of the data from Aesch showed fairly good agreement (correlation coefficient 0.91-0.98). However, to our knowledge it is only possible to calibrate the wind components and not the fluxes. 
The used thermocouples were compared for a short time during the set-up and showed good agreement (U. Eichelmann 2006, personal communication). All thermocouples referred to one reference point and were logged with the same data logger. Additionally all measurements of the thermocouples (DOY 185-185) were compared in a linear regression and showed good agreement with a slope near unity $( \pm 0.1)$, an offset between -0.1 and -0.07 and a correlation coefficient of 0.99 . No mean bias could be detected. Similar good agreement was found for the thermocouples in the trunk space. An estimation of uncertainty was made for the mean diurnal course of non-turbulent horizontal advection above the canopy. Therefore the absolute errors in length measurement and wind measurement were estimated $( \pm 0.01 \mathrm{~m}$ and $\pm 0.01 \mathrm{~m} \mathrm{~s}^{-1}$, respectively). The absolute error in temperature measurement was estimated at $0.01^{\circ} \mathrm{C}$. However, following the law of error propagation, this resulted in a mean error of more than $50 \%$ for the non-turbulent horizontal advection. This indicates a large uncertainty of the calculated non-turbulent horizontal advection, and probably applies to horizontal flux divergence too.

\section{References}

Aubinet M, Grelle A, Ibrom A, Rannik Ü, Moncrieff J, Foken T, Kowalski AS, Martin PH, Berbgier P, Bernhofer C, Clement R, Elbers J, Granier A, Grünwald T, Morgenstern K, Pilegaard K, Rebmann C, Snijders W, Valentini R, Vesala T (2000) Estimates of the annual net carbon and water exchange of forests: The EUROFLUX methodology. Adv Ecol Res 30:113-175

Aubinet M, Chermanne B, Vandenhaute M, Longdoz B, Yernaux M, Laitat E (2001) Long term carbon dioxide exchange above a mixed forest in the Belgian Ardennes. Agric For Meteorol 108:293-315

Aubinet M, Heinesch B, Yernaux M (2003) Horizontal and vertical $\mathrm{CO}_{2}$-advection in a sloping forest. Boundary-Layer Meteorol 108:397-417

Aubinet M, Berbigier P, Bernhofer C, Cescatti A, Feigenwinter C, Granier A, Grünwald T, Havrankova K, Heinesch B, Longdoz B, Marcolla B, Montagnani L, Sedlak P (2005) Comparing $\mathrm{CO}_{2}$ storage and advection conditions at night at different CARBOEUROFLUX sites. Boundary-Layer Meteorol 116:63-94

Baldocchi D, Finnigan J, Wilson K, Paw U, K. T., Falge E (2000) On measuring net ecosystem carbon exchange over tall vegetation on complex terrain. Boundary-Layer Meteorol 96:257-291

Bernhofer C, Aubinet M, Clement R, Grelle A, Grünwald T, Ibrom A, Jarvis P, Rebmann C, Schulze E-D, Tenhunen JD (2003) Spruce forests (Norway and Sitka Spruce, Including Douglas Fir): carbon and water fluxes and balances, ecological and ecophysiological determinants. In: Valentini R (ed) Fluxes of carbon, energy and water of European forests, ecological studies, vol 163. Springer, Berlin, pp 99-123

Bernhofer C, Feigenwinter C, Grünwald T, Vogt R (2003a) Spectral correction of water and carbon flux for EC measurements at the anchor station tharandt. In: Bernhofer C (ed) Tharandter Klimaprotokolle, vol 8. Dresden University of Technology, Dresden, pp 1-13

Bernhofer C, Köstner B (2003) Vertical transports of trace gases at anchor stations and their spatial/temporal extrapolation under complex natural conditions. AFO2000 Newslett 2:3-6

Bernhofer C, Vogt R (1999) Energy balance closure gaps - a methodical problem of Eddy covariance measurements? In: Dear RJ, Kalma JD, Oke TR, Auliciems A (eds) Biometeorology and urban climatology at the turn of the millennium: Selected papers from the conference ICB-ICUC'99 (Sydney, 8-12. November 1999), pp 199-203

Bernhofer C (1992) Applying a simple three-dimensional Eddy correlation system for latent and sensible heat flux to contrasting canopies. Theor Appl Climatol 46:163-172

Blanford JH, Bernhofer C, Gay LW (1991) Energy flux mechanism over a Pecan Orchard Oasis. In: Proceedings, 20th Agricultural and Forest Meteorology. Conference, Salt Lake City, UT, American Meteorological Society, 45 Beacon St., Boston, MA, pp 116-119

Eugster W, Senn W (1995) A cospectral correction model for measurement of turbulent $\mathrm{NO}_{2}$ flux. Boundary-Layer Meteorol 74:321-340

Feigenwinter C, Bernhofer C, Vogt R (2004) The influence of advection on short term $\mathrm{CO}_{2}$ budget in and above forest canopy. Boundary-Layer Meteorol 113:201-224 
Finnigan JJ (1999) A comment on the paper by Lee (1998): "On micrometeorological observations of surface-air exchange over tall vegetation". Agric For Meteorol 97:55-67

Goulden ML, Munger JW, Song-Miao F, Daube BC, Wofsy SC (1996) Measurements of carbon sequestration by long-term Eddy covariance: methods and a critical evaluation of accuracy. Global Change Biol 2:169-182

Grelle A, Lindroth Q (1996) Eddy-correlation system for long-term monitoring fluxes of heat, water vapour and $\mathrm{CO}_{2}$. Global Change $\mathrm{Biol} 2: 297-307$

Grünwald T (2002) Langfristige Beobachtungen von Kohlendioxidflüssen mittels Eddy-KovarianzTechnik über einem Altfichtenbestand im Tharandter Wald. Ph.D. Dissertation, Dresden University of Technology, Dresden, Germany, 124 pp

Kaimal JC, Wyngaard JC, Coté OR (1972) Spectral characteristics of surface-layer turbulence. Quart J Roy Meteorol Soc 98:563-589

Lee X (1998) On micrometeorological observations of surface-air exchange over tall vegetation. Agric For Meteorol 91:39-49

Lee X, Hu X (2002) Forest-air fluxes of carbon, water and energy over non-flat terrain. BoundaryLayer Meteorol 103:277-301

Lee X (2004) Forest-air exchange in non-ideal conditions: the role of horizontal flux and its divergence. In: Mencuccini M, Grace J, Moncrieff J, McNaughton KG (eds) Forest at the land-atmosphere interface. CABI Publishing, Cambridge, pp 145-157

Marcolla B, Cescatti A, Montagnani L, Manca G, Kerschbaumer G, Minerbi S (2005) Importance of advection in the atmospheric $\mathrm{CO}_{2}$ exchanges of an alpine forest. Agric For Meteorol 130:193-206

Mellmann P (1998) Die Bedeutung der Speicherterme bei zeitlich hochauflösender Verdunstungsbestimmung am Beispiel des Tharandter Waldes. Diploma thesis, Dresden University of Technology, Dresden, Germany

Panin GN, Tetzlaff G, Raabe A (1998) Inhomogeneity of the land surface and problems in parameterisation of the surface fluxes in natural conditions. Theor Appl Climatol 60:163-178

Paw UKT, Baldocchi D, Meyers TP, Wilson KB (2000) Correction of Eddy-covariance measurements incorporation both advective effects and density fluxes. Boundary-Layer Meteorol 97:487-511

Pilegaard K, Hummelshj P, Jensen NO, Chen Z (2001) Two years of continuous $\mathrm{CO}_{2}$ Eddy-flux measurements over a Danish beech forest. Agric For Meteorol 107:29-41

Queck R (2004) Fraktionierung und zeitliche Differenzierung von Depositionsraten in Waldbeständen. Ph.D. Dissertation, Dresden University of Technology, Dresden, Germany, $234 \mathrm{pp}$

Rebmann C, Göckede M, Foken T, Aubinet M, Aurela M, Berbigier P, Bernhofer C, Buchmann N, Carrara A, Cescatti A, Ceulemans R, Clement R, Elbers JA, Granier A, Grünwald T, Guyon D, Havrankova K, Heinesch B, Knohl A, Laurila T, Longdoz B, Marcolla B, Markkanen T, Miglietta F, Moncrieff J, Montagnani L, Moors E, Nardino M, Ourcival J-M, Rambal S, Rannik Ü, Rotenberg E, Sedlak P, Unterhuber G, Vesala T, Yakir D (2005) Quality analysis applied on Eddy covariance measurements at complex forest sites using footprint modelling. Theor Appl Climatol $80: 121-141$

Schotanus P, Nieuwstadt FTM, De Bruin HAR (1983) Temperature measurement with a sonic anemometer and its application to heat and moisture fluxes. Boundary-Layer Meteorol 26:81-93

Staebler RM, Fitzjarrald DR (2004) Observing subcanopy $\mathrm{CO}_{2}$ advection. Agric For Meteorol 122:139-156

Valentini R, De Angelis P, Matteucci G, Monaco R, Dore S, Scarascia Mucnozza GE (1996) Seasonal net carbon dioxide exchange of a beech forest with the atmosphere. Global Change Biol 2:199-207

Valentini R (ed) (2003) Fluxes of carbon, water and energy of European forests, ecological studies, vol 163. Springer, Berlin, $266 \mathrm{pp}$

Wilczak JM, Oncley SP, Stage SA (2001) Sonic anemometer tilt correction algorithms. BoundaryLayer Meteorol 99:127-150

Wilson K, Goldstein A, Falge E, Aubinet M, Baldocchi D, Berbigier P, Bernhofer C, Ceulemans R, Dolman H, Field C, Grelle A, Ibrom A, Law BE, Kowalski A, Meyers T, Moncrieff J, Monson R, Oechel W, Tenhunen J, Valentini R, Verma S (2002) Energy balance closure at FLUXNET sites. Agric For Meteorol 113:223-243

Wyngaard JC, Rockwell L, Izumi Y (1971) Local free convection similarity and the budgets of shear stress and heat flux. J Atmos Sci 28:1171-1182

Yi C, Davis KJ, Bakwin PS, Berger BW, Marr LC (2000) Influence of advection on measurements of the net ecosystem-atmosphere exchange of $\mathrm{CO}_{2}$ from a very tall tower. J Geophys Res 105:9991-9999 